\title{
Sintering temperature dependence of optimized microstructure formation of BaFe12O19 using sol-gel method
}

\begin{abstract}
In an attempt to obtain the best possible properties of barium hexaferrite (BaFe12O19), the solï gel synthesis method was chosen and, the optimum sintering conditions were established. The effects of the sintering temperature on the structural, morphological and magnetic properties of hexaferrite were studied. X-ray analysis indicates that the sintered samples $\left(1,000 \mathrm{i} 1,150{ }^{\circ} \mathrm{C}\right)$ remained in the hexagonal structure. From this analysis, no secondary phases are identified. The effect of sintering temperature on the grain growth of $\mathrm{BaFeBaFe} 12 \mathrm{O} 19$ is confirmed by the microstructure using HR-SEM and is in good agreement with the XRD analysis based on the peak intensity of the (107) plane. The samples sintered at $1,150{ }^{\circ} \mathrm{C}$ showed the densities as $\sim 93 \%$ of theoretical density. Sintering temperature affected the grains in compact samples. The results show that homogeneous and dense $\mathrm{BaFeBaFe} 12 \mathrm{O} 19$ ceramics obtained at a lower sintering temperature of $1,150{ }^{\circ} \mathrm{C}$ which is lower than the normally reported sintering temperature of Ól,200 ${ }^{\circ} \mathrm{C}$. The thermal treatment can markedly affect the grains in compact samples.
\end{abstract}

Keyword: BaFe12O19; Sintering temperature; Solï gel method 